\title{
Analysis of Biomarkers of DNA Damage and Mutagenicity in Mice Exposed to Acrylonitrile
}

Vernon E. Walker, ${ }^{*},+,, \S$, Dale M. Walker, ${ }^{\S}, \|$ Burhan I. Ghanayem, ${ }^{* *},{ }^{\perp}$ and George R.

Douglas, $* *, \mathbb{I}$

†Wadsworth Center, New York State Department of Health, Albany, New York 12201, USA Department of Pathology and Laboratory Medicine, University of Vermont, Burlington, VT 05405, USA

${ }^{\S}$ The Burlington HC Research Group, Inc., Jericho, VT 05465, USA

"Experimental Pathology Laboratories, Sterling VA 20167, USA

${ }^{\perp}$ National Institute of Environmental Health Sciences, Research Triangle Park, NC 27709, USA

IEnvironmental Health Science and Research Bureau, Health Canada, Ottawa, Ontario K1A 0K9, Canada

*Corresponding Author: E-mail: vwalker@uvm.edu, Phone: 802-777-9394.

**These authors contributed equally to this work, each having designed and directed interfacing projects: Animal exposures and genotoxicity studies in cytochrome P450 2E1-null mice and matched wild-type mice were conducted at the National Institute of Environmental Health Sciences and animal exposures and mutation studies in the MutaMouse strain were performed at Health Canada 
Table S1. DNA Damage in Tissues of Mice Exposed to Acrylonitrile, Evaluated after Standard Electrophoresis $^{a}$

\begin{tabular}{|c|c|c|c|c|c|c|}
\hline $\begin{array}{l}\text { Tissue, Dose }(\mathrm{mg} / \mathrm{kg}) \text {, } \\
\text { and Genotype }{ }^{b}\end{array}$ & $\begin{array}{l}\text { Migrated } \\
\text { DNA }(\%)\end{array}$ & $\begin{array}{l}\text { Tail length } \\
(\mu \mathrm{m})\end{array}$ & $\begin{array}{l}\text { Olive tail } \\
\text { movement }^{c}\end{array}$ & $\begin{array}{l}\text { Pairwise } \\
p_{\text {-value }}{ }^{d}\end{array}$ & $\begin{array}{l}\text { Cells with LMW } \\
\text { DNA }(\%)^{e}\end{array}$ & $\begin{array}{l}\text { Pairwise } \\
p \text {-value }\end{array}$ \\
\hline \multicolumn{7}{|l|}{ Liver } \\
\hline Control WT & $14.2 \pm 1.69$ & $33.1 \pm 1.48$ & $2.4 \pm 0.35$ & & $18 \pm 3.13$ & \\
\hline $20 \mathrm{WT}$ & $27.1 \pm 2.48$ & $52.0 \pm 3.29$ & $5.9 \pm 0.71$ & $0.001 *$ & $18 \pm 4.85$ & 0.500 \\
\hline Control CYP2E1-null & $16.2 \pm 3.77$ & $30.8 \pm 3.01$ & $3.0 \pm 0.86$ & & $8.6 \pm 3.17$ & \\
\hline 60 CYP2E1-null & $15.6 \pm 0.99$ & $29.3 \pm 1.78$ & $2.6 \pm 0.17$ & 0.661 & $12.6 \pm 3.09$ & 0.196 \\
\hline \multicolumn{7}{|l|}{ Ovary } \\
\hline Control WT & $19.5 \pm 1.78$ & $40.0 \pm 2.36$ & $3.5 \pm 0.40$ & & $26.0 \pm 3.18$ & \\
\hline $20 \mathrm{WT}$ & $18.4 \pm 2.53$ & $39.0 \pm 2.15$ & $3.2 \pm 0.54$ & 0.665 & $18.4 \pm 3.59$ & 0.924 \\
\hline Control CYP2E1-null & $9.2 \pm 1.00$ & $25.0 \pm 2.31$ & $1.3 \pm 0.19$ & & $15.4 \pm 5.71$ & \\
\hline 60 CYP2E1-null & $13.4 \pm 1.00$ & $32.3 \pm 1.15$ & $2.0 \pm 0.20$ & $0.022 *$ & $20.8 \pm 4.04$ & 0.231 \\
\hline \multicolumn{7}{|l|}{ Harderian Gland } \\
\hline Control WT & $22.6 \pm 2.19$ & $34.7 \pm 1.79$ & $4.0 \pm 0.55$ & & $68.6 \pm 1.60$ & \\
\hline $20 \mathrm{WT}$ & $19.0 \pm 2.89$ & $27.4 \pm 2.38$ & $3.2 \pm 0.56$ & 0.853 & $58.4 \pm 8.45$ & 0.865 \\
\hline Control CYP2E1-null & $21.5 \pm 2.75$ & $33.4 \pm 5.02$ & $3.8 \pm 0.78$ & & $53.2 \pm 6.49$ & \\
\hline 60 CYP2E1-null & $16.9 \pm 1.41$ & $27.4 \pm 1.89$ & $2.7 \pm 0.36$ & 0.884 & $63.4 \pm 4.49$ & 0.116 \\
\hline \multicolumn{7}{|l|}{ Lung } \\
\hline Control WT & $25.8 \pm 6.54$ & $68.5 \pm 7.13$ & $7.0 \pm 2.09$ & & $23.8 \pm 9.30$ & \\
\hline $20 \mathrm{WT}$ & $26.7 \pm 1.79$ & $69.7 \pm 2.35$ & $7.2 \pm 0.60$ & 0.468 & $15.6 \pm 6.02$ & 0.760 \\
\hline Control CYP2E1-null & $36.1 \pm 5.86$ & $71.1 \pm 3.66$ & $9.9 \pm 1.86$ & & $31.6 \pm 7.40$ & \\
\hline 60 CYP2E1-null & $42.1 \pm 5.47$ & $73.3 \pm 6.34$ & $11.5 \pm 1.87$ & 0.291 & $15.2 \pm 4.14$ & 0.955 \\
\hline \multicolumn{7}{|l|}{ Glandular stomach } \\
\hline Control WT & $19.9 \pm 5.05$ & $35.8 \pm 5.87$ & $4.1 \pm 1.34$ & & $15.6 \pm 3.71$ & \\
\hline $20 \mathrm{WT}$ & $18.2 \pm 2.16$ & $37.2 \pm 1.62$ & $3.7 \pm 0.54$ & 0.610 & $15.8 \pm 3.71$ & 0.485 \\
\hline Control CYP2E1-null & $24.6 \pm 3.24$ & $42.4 \pm 2.97$ & $5.0 \pm 1.08$ & & $14.8 \pm 3.89$ & \\
\hline 60 CYP2E1-null & $37.4 \pm 6.14$ & $50.2 \pm 3.52$ & $8.9 \pm 1.87$ & 0.056 & $18.4 \pm 3.23$ & 0.249 \\
\hline
\end{tabular}

\footnotetext{
${ }^{a}$ Tissues were collected $24 \mathrm{~h}$ after 6 weeks of daily doses ( 5 days/week) of acrylonitrile by gavage. Processed cells from tissues were electrophoresed for a standard time $(20 \mathrm{~min})$. Data are based on 100 cells per mouse, with 5 animals/dose group and genotype and are presented as mean \pm SE.

${ }^{b}$ Genotypes: wild-type (WT) or CYP2E1-null for cytochrome P450 2E1 deficient mice.

${ }^{c}$ Tail length measured from estimated leading edge of the head; Olive tail moment $=($ distance between the center of gravity of the DNA distribution in the tail and the center of gravity of the DNA distribution in the head) $\times$ (the fraction of DNA in the tail).

${ }^{d}$ One-tailed pairwise comparison of Olive tail moment for each treatment group to the control group (Student's $t$-test).

${ }^{e}$ Low molecular weight (LMW) DNA.

${ }^{f}$ Pairwise comparison using Mann-Whitney test.

* Significantly different at $p<0.05$ for the pairwise tests.
} 
Table S2. Dose-response for Hprt mutant T-cells in spleens of female wild-type B6C3F1 versus CYP2E1-null mice following repeated daily doses of acrylonitrile ${ }^{a}$

\begin{tabular}{cccc}
\hline Mouse Genotype and & Average Observed $\mathrm{M} f$ & Average Induced $\mathrm{M} f$ & $p$-value \\
Daily Dose & $\left(\times 10^{-6}\right)$ & $\left(\times 10^{-6}\right)$ & \\
$(\mathrm{mg} / \mathrm{kg} /$ day $)$ & & \\
\hline
\end{tabular}

Wild-type B6C3F1

mice

$\begin{array}{cccc}0 & 1.7 \pm 0.9^{b} & & \\ 2.5 & 2.3 \pm 1.9 & 0.6 & 0.60 \\ 10 & 3.1 \pm 1.2 & 1.4 & 0.063 \\ 20 & 5.4 \pm 2.4 & 3.7 & 0.016^{*}\end{array}$

CYP2E1-null mice

$1.7 \pm 0.9^{b}$

20

$1.6 \pm 0.7$

0

0.80

60

$5.3 \pm 2.3$

3.6

$0.002 *$

\footnotetext{
${ }^{a}$ Mice (6 weeks of age) were given daily doses of acrylonitrile by gavage for 4 weeks (5 days/week), and Hprt mutant frequencies ( $\mathrm{M} f \mathrm{~s})$ were measured 24 hours after the last day of dosing $(n=11$ 13/group for each genotype).

${ }^{\mathrm{b}}$ Hprt $\mathrm{M} f \mathrm{~s}$ in individual sham-exposed wild-type mice $(n=12)$ ranged from 0.6 to $2.8 \times 10^{-6}$, with a more exact mean $\mathrm{M} f$ of $1.71 \pm 0.24$ (standard error of the mean) $\times 10^{-6}$, while Hprt $\mathrm{M} f \mathrm{~s}$ in individual sham-exposed CYP2E1-null mice $(\mathrm{n}=11)$ ranged from 0.5 to $2.8 \times 10^{-6}$, with a more exact mean $\mathrm{M} f$ of $1.69 \pm 0.27$ (standard error of the mean) $\times 10^{-6}$.

* Significantly different at $p<0.05$ for pairwise tests, Mann-Whitney U-statistic or Student's t-test.
} 